\title{
Internal Mixing of Pollutants for Submicron Particles Observed during Springtime in Japan
}

\author{
Jun Matsumoto ${ }^{1), a, *}$, Masahiro Narukawa ${ }^{1), b}$, Kenshi Takahashi ${ }^{1), c}$, Yutaka Matsumi ${ }^{1), *}$, \\ Akihiro Yabushita $^{2),}$, Atsushi Shimizu ${ }^{3)}$, Ichiro Matsui ${ }^{3)}$ and Nobuo Sugimoto ${ }^{3)}$ \\ ${ }^{1)}$ Solar-Terrestrial Environment Laboratory, Nagoya University, Furo-cho, Chikusa-ku, Nagoya, Aichi 464-8601, Japan \\ ${ }^{2)}$ Horiba Ltd., 2 Miyanohigashi, Kisshoin, Minami-ku, Kyoto 601-8510, Japan \\ ${ }^{3}$ National Institute for Environmental Studies, 16-2 Onogawa, Tsukuba, Ibaraki 305-8506, Japan \\ Present affiliations: \\ ${ }^{\mathrm{a} C e n t e r ~ f o r ~ P r i o r i t y ~ A r e a s, ~ T o k y o ~ M e t r o p o l i t a n ~ U n i v e r s i t y, ~ J a p a n ~}$ \\ ' $\mathrm{IHI}$ Corporation, Japan \\ cPioneering Research Unit for Next Generation, Kyoto University, Japan \\ ${ }^{\mathrm{d} D e p a r t m e n t ~ o f ~ M o l e c u l a r ~ E n g i n e e r i n g, ~ K y o t o ~ U n i v e r s i t y, ~ J a p a n ~}$
}

*Corresponding author. Tel: +81-42-677-3146, E-mail: jmatsu@tmu.ac.jp

Tel: +81-52-747-6412, E-mail: matsumi@stelab.nagoya-u.ac.jp

\begin{abstract}
Internally mixed states of submicron particles during transport from the Asian continent to the Pacific Ocean were analyzed using a single-particle time-offlight mass spectrometer. The observation was conducted at Tsukuba in Japan in the spring of 2005 in order to investigate springtime transport of particles from the continent. The sum of ion intensities of sulfate $\left(\mathrm{HSO}_{4}^{-}\right)$detected in particles originating from the continental air masses counted for $75 \%$ of that in all particles during the observation. By analyzing correlations among compounds, origins and internally mixed states of compounds were estimated. It was found that nitrate was mixed with sulfate-rich particles as the air mass approached Japan. It was confirmed that Asian mineral dust particles played significant roles for transport of continental sulfate to Japan. As a result of analysis on internal mixing of chlorine and nitrate, it was implied that the chlorine loss in fine sea salt particles had already proceeded at Tsukuba. It was characteristic that fluoride ions were significantly detected, coal combustion in the Asian Continent can be an important source of fluorides detected in Japan through the westward transportation of fine particles including fluorides.
\end{abstract}

Key words: Internally mixed state, Asian mineral dust, Single-particle analysis, TOFMS, Negative ion, Ternary plot

\section{INTRODUCTION}

Atmospheric aerosols play a critical role in atmos- pheric sciences in view of solar radiation, heterogeneous reactions in the atmosphere, and human health. Hence, it is essential to understand the source, transport and transformation of atmospheric particles and their components. It has been reported that the emissions of pollutants have been increasing and so the importance of aerosols has been growing in these past few decades. This trend has been noted in Asian developing countries (Huebert et al., 2003). Globally, it has been reported that aerosols from Asia can influence the air quality even in other regions, for example, North America (DeBell et al., 2004). In terms of cross-border pollution, atmospheric acidification, and nutrient supply to the ocean, it is important to find out the mechanisms of transport of tracer compounds from the Asian Continent toward Japan, the Pacific Ocean, and North America. The identification of the chemical compositions of aerosols is essential for understanding the interactions between the aerosols and adsorbed pollutants (Mori et al., 2003; Xiao et al., 1997). As an outstanding phenomenon, Asian mineral dust has been focused (Uematsu et al., 1983), as they can play a role as the carrier of pollutants (Nishikawa et al., 1991). The mixed states of chemical components are important to understand the histories and characteristics of the particles. Mori et al. (2003) explored the mixed states of coarse Asian dust aerosols with sulfate and nitrate in Japan using a high-volume sampler. They investigated the relationship between nitrate quantities and the average surface areas of filter-sampled particles, and indicated that nitrate was attached to the surface of the particles as total. Several studies were reported to know the internally mixed states, which present the chemical components coexisting in individual single particles. Zhang et al. (2005) reported the 
mixed states of Asian dust at coastal areas of China by an energy dispersive X-ray spectrometer. They indicated that the dust plume from the inland China did not mix with polluted air from the coastal area. Bates et al. (2004) discussed dust and pollutant transport during the campaign 'ACE-Asia', which was conducted onboard a ship in the marine boundary layer near the continent. However, in situ, real-time observation of the internally mixed states is still insufficient.

In this decade, a number of real-time measurements have been conducted on aerosols using mass spectrometry (Middlebrook et al., 2003; Suess and Prather, 1999). Aerosol Mass Spectrometer (AMS) have been applied to quantify the chemical compositions of aerosols (Jayne et al., 2000). To examine the internally mixed states, several techniques for analyzing single particles have been developed by using the combination of laser ionization and mass spectrometry (Sullivan et al., 2007a, b; Murphy et al., 2006; Thomson et al., 2000; Gard et al., 1997; Murphy and Thomson, 1995). Recently, we reported the first observation of Asian mineral dust far downstream of the Asian continental outflow (Matsumoto et al., 2006). The uptake of sulfates and nitrates onto Asian dust particles during transport from the Asian continent to the Pacific Ocean was analyzed using a single-particle time-of-flight mass spectrometer. It was found that sulfate-rich dust particles made their largest contribution during the 'dust event'. As a result of detailed analysis including backward trajectory calculations, it was confirmed that sulfate components originating from coal combustion in the continent were internally mixed with dust particles. Asian dust plays a critical role as the carrier of sulfate over the Pacific Ocean. Sullivan et al. (2007a, b) recently reported the results of their single-particle observations by the Aerosol Time of Flight Mass Spectrometer (ATOFMS; Suess and Prather, 1999) during the 'ACE-Asia' campaign in 2001. They discussed internally mixed states of Asian mineral dust observed in the marine boundary layer along the continent. They found that high amount of sulfate accumulate on aluminosilicate-rich dust possibly owing to oxidation by iron in the dust.

In this study, the single-particle mass spectrometer was partly improved to increase the rate of particle detection and the additional observation was conducted during the springtime in 2005 in Japan. The aim of this observation is to capture internally mixed states of submicron particles downstream of the continental outflow. Transport of particles from the continent to Japan occurs in springtime and this season is suitable for the investigation of the effect of transport on the chemical composition of aerosols over Japan. Correlations among various components were explored to discuss the observed internally mixed states.

\section{EXPERIMENTS AND METHODS}

\section{1 Single Particle TOFMS Instrument}

The fundamental description of the single-particle TOFMS instrument has been reported in previous literatures (Narukawa et al., 2008, 2007a, b; Matsumoto et al., 2006). Thus, only a brief description of the instrument and its improvement are summarized here.

The instrument used in this study consisted of four sections: (a) introduction of the atmospheric particles into the vacuum chamber of the instrument, (b) detection of the particles by laser scattering, (c) desorption/ ionization of the particles, and (d) a time-of-flight mass spectrometer for analyzing the composition of particles. The beam of particles was aligned horizontally by a series of aerodynamic lenses and introduced into the chamber for particle detection. The pressure in the particle-detection chamber was $10^{-2} \mathrm{~Pa}$ when the flow rate of the sample was set to $500 \mathrm{sccm}\left(\mathrm{cm}^{3} \mathrm{~min}^{-1}\right.$ at standard conditions). A continuous wave (cw) visible laser was directed at $60^{\circ}$ to the incident particle beam, and light scattered by the particle was monitored using a photomultiplier (PMT; Hamamatsu, 1P28A) at a $60^{\circ}$ angle to the laser beam. The intensity of the scattered cw laser light was monitored to estimate the physical size of the particles. The relationship between the diameter of the particles and the intensity of the scattered light was explored using size-known polystyrene latex (PSL) particles by reference to Lee et al. (2002). After a particle was detected from the scattered light, a pulsed excimer laser (Lambda Physik, Optex, $248 \mathrm{~nm}, 5 \mathrm{~mJ}$ pulse ${ }^{-1}$ ) was fired to desorb and ionize the particle. After ablation and ionization, ions were accelerated and deflected by electric fields, introduced into the time-of-flight (TOF) chamber, and detected by a multi-channel plate detector. To measure both positive and negative ions by the single TOF system, the polarities of the electric fields were switched automatically every minute. Thus, our TOFMS instrument gives information about chemical components of individual particles from the mass spectra and about particle sizes from the light scattering intensities.

\section{2 Observation in Japan}

The instrument was installed on the 8th floor (about $30 \mathrm{~m}$ from the ground) of the tower for LIDAR observation at the National Institute for Environmental Studies (NIES), Tsukuba, Japan $\left(140.12^{\circ} \mathrm{E}, 36.05^{\circ} \mathrm{N}\right)$, which is located about $50 \mathrm{~km}$ from the coastline of the Pacific Ocean. A detailed description of this site 


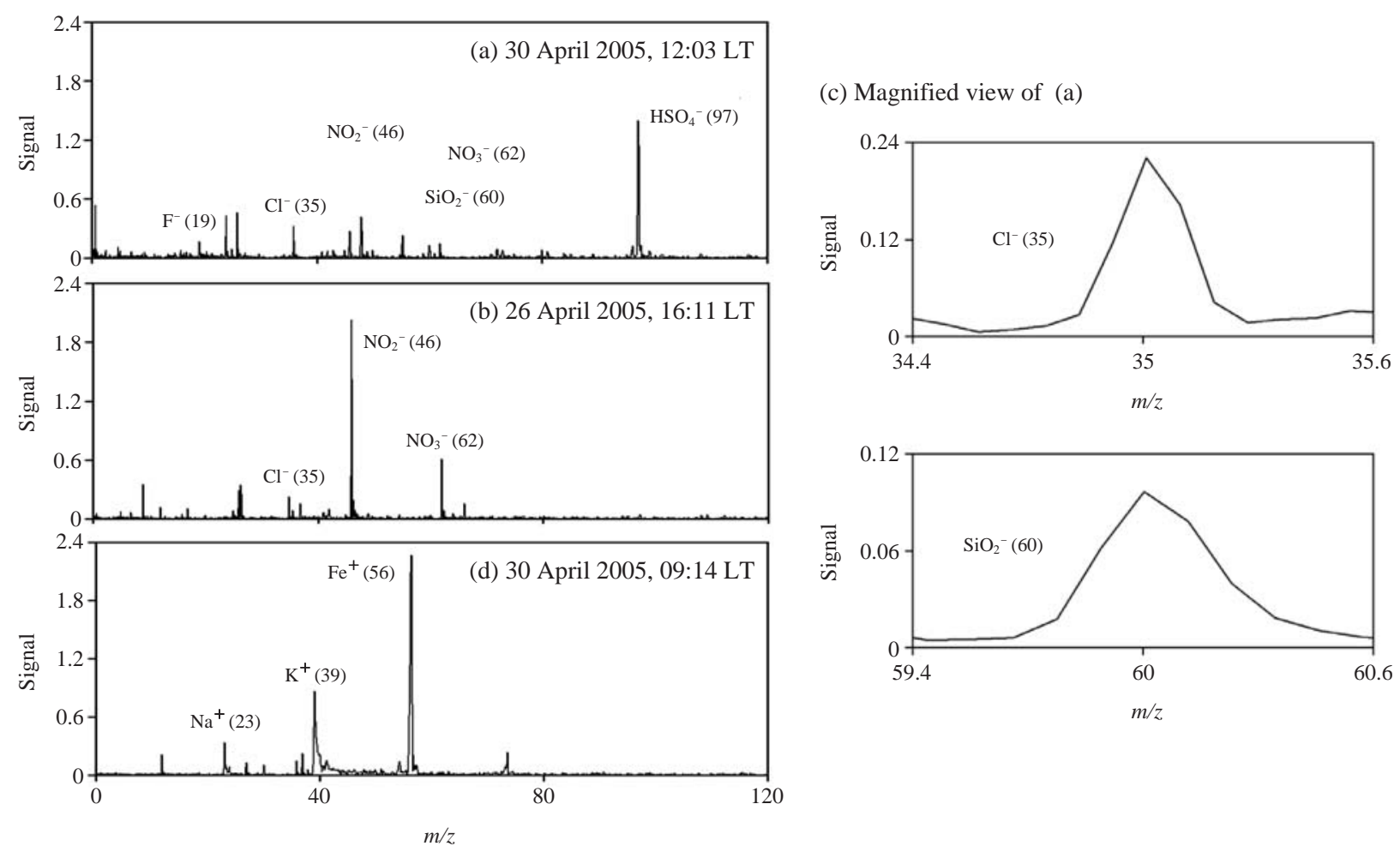

Fig. 1. Examples of TOFMS spectra of negative ions for (a) an ambient particle observed during Asian dust event on 30 April 2005, an example for sulfate-rich particle and (b) an ambient particle observed on 26 April 2005, an example for nitrate-rich particle. (c) Magnified view of $\mathrm{Cl}^{-}(\mathrm{m} / \mathrm{z}=35)$ and $\mathrm{SiO}_{2}{ }^{-}(\mathrm{m} / \mathrm{z}=60)$ peaks observed in the mass spectrum (a). (d) An Example of TOFMS spectra of positive ions for an ambient particles observed during Asian dust event. Values in parentheses are corresponding mass numbers, $\mathrm{m} / \mathrm{z}$. 'LT' represents the local time in Japan.

was presented elsewhere (Shimizu et al., 2004). The observation was conducted for 25 days, from April 22 to May 16, 2005. Although it should be noted that there was missing data on 27 April due to instrumental failure, during the field observation, negative and positive ion spectra were analyzed for 23,418 and 42,395 particles, respectively.

The incidences of Asian dust events were predicted by regional chemical weather forecasting system, CFORS (Uno et al., 2003), and confirmed by the observation by LIDAR of non-spherical dust particles in the boundary layer at the site (Shimizu et al., 2004). To categorize the source of air mass, the NOAA HYSPLIT Model (version: 4; vertical motion: model vertical velocity; meteorological data set: FNL) was adopted to calculate the backward trajectories that reached the site (the model can be accessed at: http://www.arl.noaa. gov/ready/open/hysplit4.html). 96-hour backward trajectories were acquired for every 12 hours during the campaign (with end time of 00:00 and 12:00 universal time (UT)). Three initial heights were set to $500,1,000$, and $1,500 \mathrm{~m}$, respectively, to validate the convergence.
Fig. 1a shows a typical negative mass spectrum of an ambient particle observed on 30 April 2005. According to the CFORS prediction, LIDAR observation, and HYSPLIT calculation, the period from 28 to 30 April 2005 was considered as an Asian dust event at Tsukuba. The signal intensities depend on the amount and sensitivity of the instrument for each component. Fig. 1b shows a typical mass spectrum of an ambient particle observed on 26 April 2005. Remarkable peaks in these mass spectra such as $\mathrm{NO}_{2}{ }^{-}, \mathrm{NO}_{3}{ }^{-}$and $\mathrm{HSO}_{4}{ }^{-}$ indicate the high sensitivity of the instrument for these species and their amounts and were evidence that nitrate and sulfate components were present in particles. Settings of the aerodynamic lens were modified and smaller particles were focused in this study than in the first campaign in 2004 (Matsumoto et al., 2006). Signals of bulk components of coarse particles such as $\mathrm{SiO}_{2}{ }^{-}$and $\mathrm{Cl}^{-}$were not dominant in mass spectra for the large majority of fine particles as shown in Fig. 1a. It is true that signals of such components were weak but they were significantly detected as shown in Fig. 1c which is a magnified view of the $\mathrm{Cl}^{-}$and $\mathrm{SiO}_{2}{ }^{-}$ peaks observed in Fig. 1a. 
The internal mixings of various compounds were observed at Tsukuba. As well as our first study of 2004, there were some particles which include both $\mathrm{SiO}_{2}{ }^{-}$ and pollutants such as $\mathrm{HSO}_{4}{ }^{-}$and $\mathrm{NO}_{3}{ }^{-}$. It was found that the Asian dust particles were transformed due to uptake of sulfate and nitrate during the transport, this transformation was successfully detected by the singleparticle TOFMS. In this study, the polarities of electric fields of the mass spectrometer were switched every minute to monitor both positive and negative ions. Positive ion spectra were useful to investigate the internally mixed states of particles, though it was not possible to capture both positive and negative ion spectra simultaneously. A typical positive ion mass spectrum is shown in Fig. 1d, this spectrum is representative of particles observed during the dust event. $\mathrm{Fe}^{+}$was significantly observed which was characteristic of Asian dust particles.

The composition of each particle was analyzed, and hence the mixed state in each particle was determined. A large number of mass spectra were categorized into several representative prototypes utilizing a neural network analysis, Adaptive Resonance Theory-2a (ART-2a), as in the observation in 2004 (Matsumoto et al., 2006). The principles were reported previously (eg. Zhao et al., 2005; Phares et al., 2001). Briefly, (1) Mass spectra are considered as vectors containing ion intensities for all $\mathrm{m} / z$; (2) The vectors are normalized; (3) The vectors are categorized into a moderate number of clusters which consist of similar vectors. As a scale of similarity between a sample vector and the cluster vector, the dot product is used. When the dot products between the sample and all clusters are less than the vigilance limit, the sample creates a new cluster. The vigilance parameter is generally set to 0.6 to control the number of cluster moderately. When a sample vector is judged as similar to a cluster, the cluster vector is revised with the sample vector included. The weight of the new sample vector, learning rate, is set at first. After the repeated calculation, a moderate number of the cluster vectors, namely as prototypes, are acquired. The ART-2a theory is a common method to analyze spectra of single particles, and it has the advantage of the automatic analysis of an enormous quantity of data. However, since the ART-2a analysis is based on the dot product between two mass spectra, the result cannot reflect the contributions of 'minor components' whose signal intensities are weak.

In this paper, ART-2a, a spectrum categorization algorithm, grouped particles of similar chemical composition typically in three types. They are sulfate-rich spectra which are characterized by a dominant signal intensity at $m / z=97\left(\mathrm{HSO}_{4}{ }^{-}\right)$as shown in Fig. 1a (hereafter sulfate-rich particles), nitrate-rich spectra which are by dominant signal intensities at $m / z=46\left(\mathrm{NO}_{2}{ }^{-}\right)$ and $62\left(\mathrm{NO}_{3}{ }^{-}\right)$as shown in Fig. $1 \mathrm{~b}$ (hereafter nitraterich particles), and others. To cover the shortcoming of the ART-2a analysis and reflect the contribution of minor components, manual analysis of peak intensities in the individual mass spectra was also performed in this study. The signal for each mass number $\mathrm{m} / \mathrm{z}$ was acquired from the peak area for the interval of $\mathrm{m} / \mathrm{z} \pm$ 0.5 . For each particle, a database including observed date and time, approximate diameter estimated by the scattered laser light, polarity of the ion judged from the electron signal $(\mathrm{m} / \mathrm{z}=0)$, peak areas of signals for selected mass numbers $(\mathrm{m} / \mathrm{z})$, and the categories of air mass origin, was constructed. Once the time series of the data is acquired, the relationship among chemical composition, physical size of the particle, and the meteorological origin of the air mass can be examined.

The origins of air masses were categorized into four

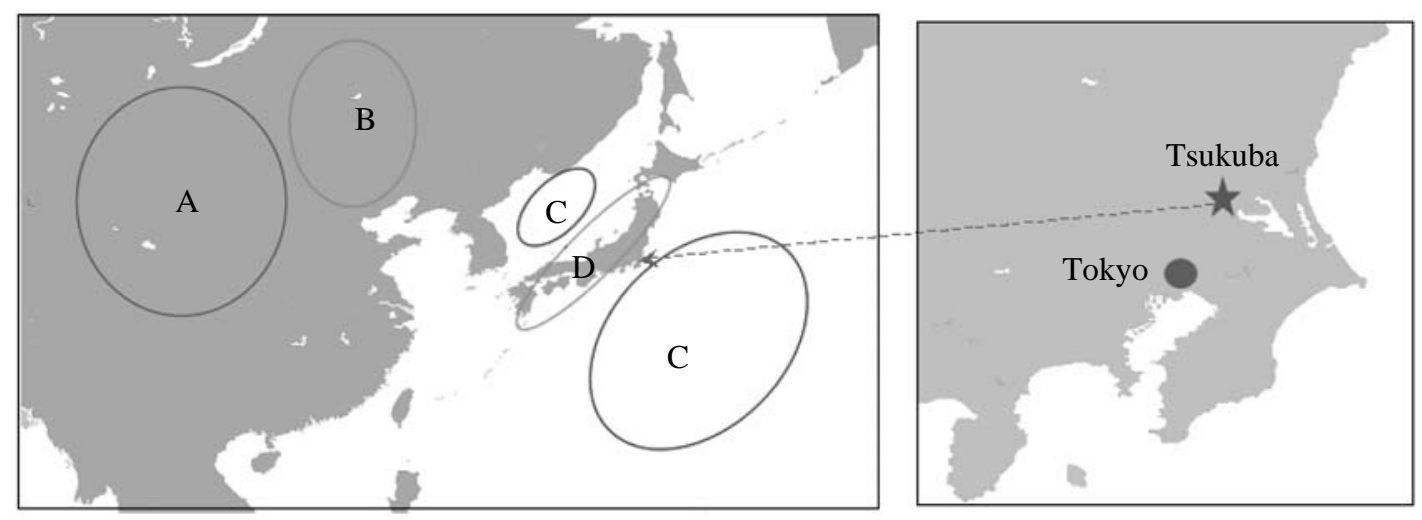

Fig. 2. The origins of air masses categorized by NOAA HYSPLIT backward trajectory calculation; air masses from (A) inland China, (B) northeast China and Siberia, (C) the sea such as Pacific Ocean and Japan Sea, and (D) domestic area in Japan. The position of the observation site, Tsukuba, is also shown marked by a star. 

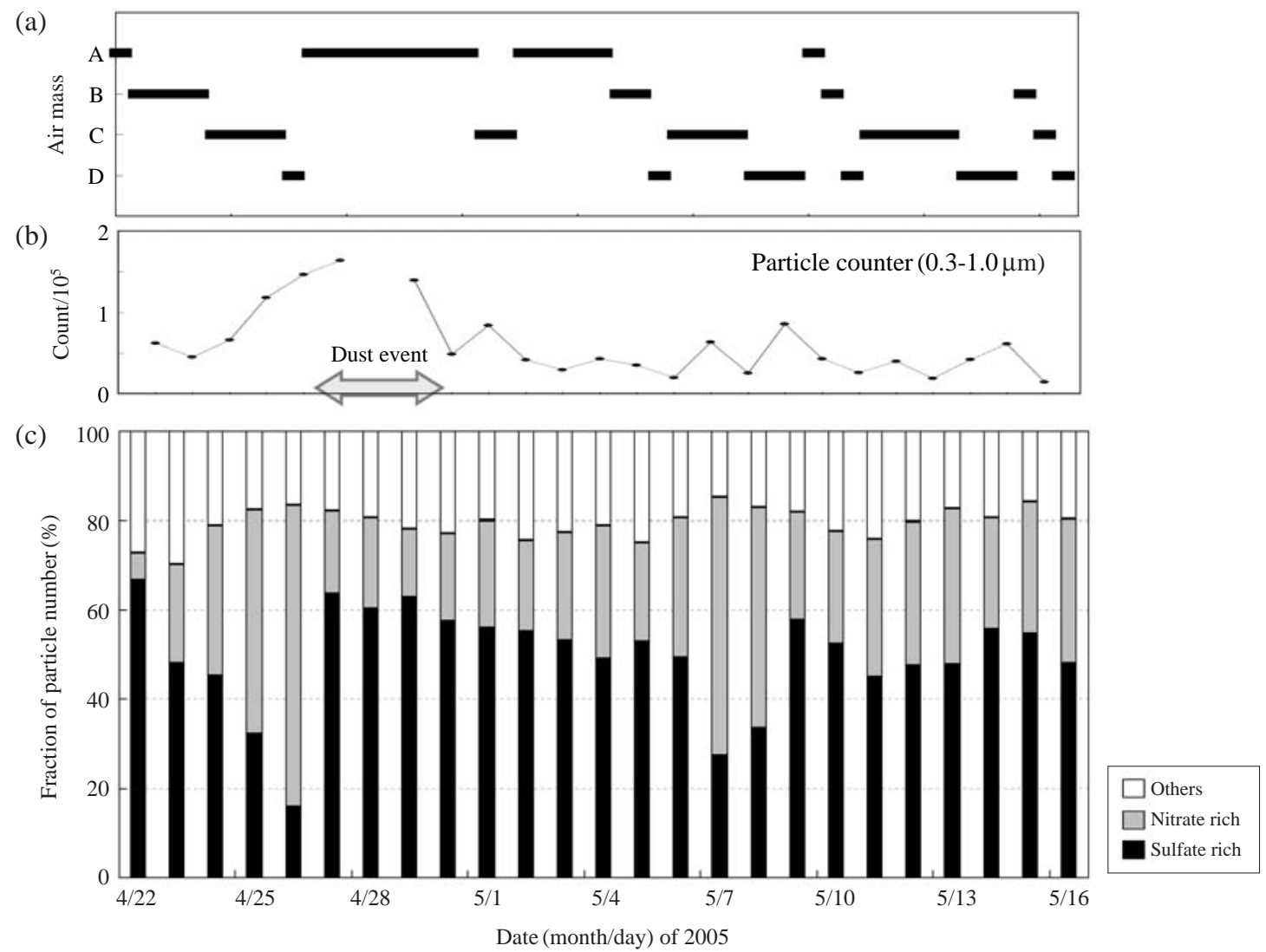

Fig. 3. Time series of (a) categories of air mass origins, (b) counts of ambient particles observed by an optical particle counter, and (c) fractions of sulfate-rich (black bars), nitrate-rich (gray bars) and other prototypes (white bars), classified by ART-2a method. The period of the dust event is also indicated.

regions, as shown in Fig. 2, as a result of backward trajectory calculations: (A) Air mass originating from inland China as a source region of the Asian dust, crossing over the coastal area of the continent where the anthropogenic emission is active. Trajectories passed over the area indicated by the circle A in Fig. 2 within 96 hours; (B) Air mass from northeastern China, crossing over Korea. Trajectories passed over the circle B in Fig. 2 within 96 hours; (C) Maritime air mass from the Pacific Ocean or Japan Sea. Trajectories traveled over the sea but did not reach to A and B and not return to D within 96 hours; (D) Regional air mass staying over domestic Japan Islands. Trajectories returning to Japan Islands within 96 hours are included. The observation point, Tsukuba, is also shown in Fig. 2 marked by a star.

\section{RESULTS AND DISCUSSION}

\subsection{ART-2a Analysis}

From the ART-2a analysis, with a vigilance para- meter of 0.60 and learning rate $0.05,23418$ negative ion spectra were categorized into 243 prototypes. As described in the previous section, from the chemical characteristics of the mass spectra, the 243 prototypes were further categorized as follows: (a) sulfate-rich particles (the number fraction was $52 \%$ ); (b) nitraterich particles $(27 \%)$; (c) other types $(21 \%)$. The time series of the fractions are plotted in Fig. 3. Note that the observed number of particles increased during the Asian dust event (28-30 April, 2005, in Fig. 3b). For the sulfate-rich particles, noticeable trends were observed as follows. It was found that the sulfate-rich particles made their largest contribution during the period of the Asian dust event when the observed number of particles reached its peak. For example, in the typical Asian dust event, Fig. 4a shows a result of backward trajectory calculations for 30 April 2005 by the NOAA HYSPLIT Model. It was confirmed that the air mass originating from the source area of Asian dust particles (category 'A' in Fig. 2) passed over the coastal area. The trajectory analysis supported that the observation at Tsukuba that there was a large influence by 
(a) 30 April 2005, am (03:00-15:00 LT) air mass from inland China (category 'A')

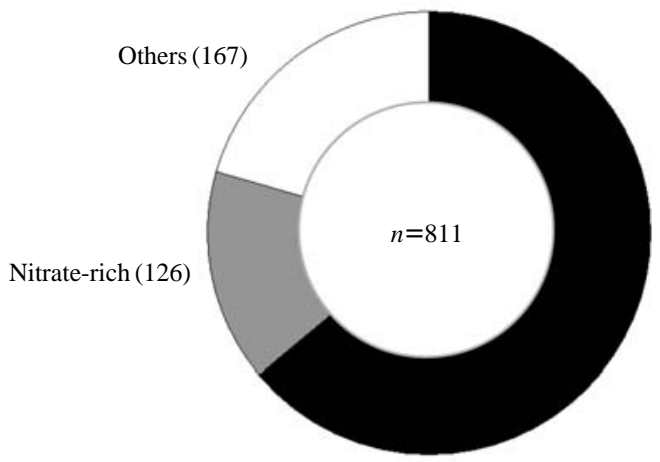

Sulfate-rich (518)

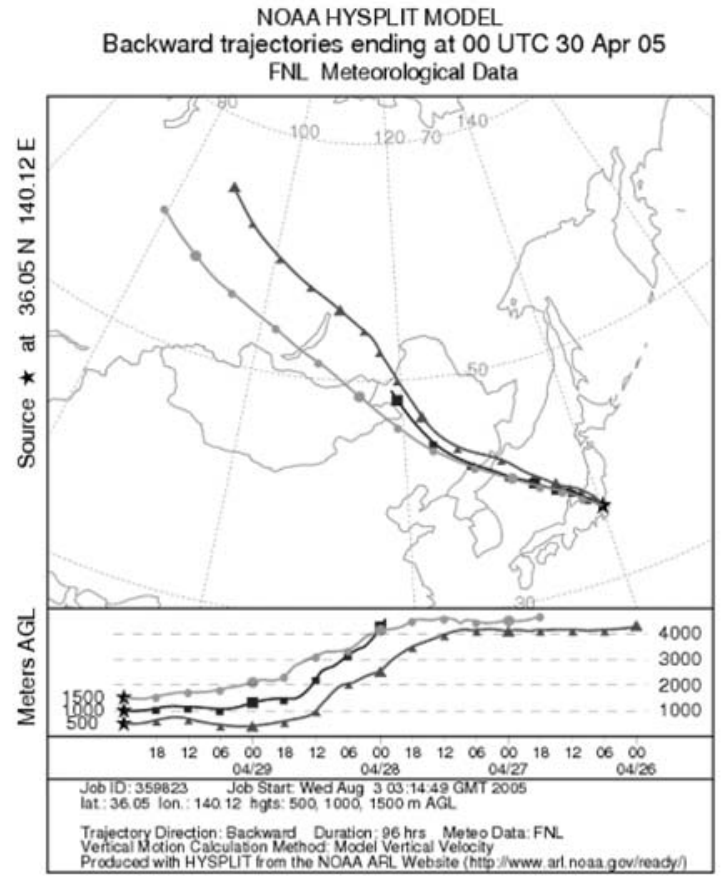

(b) 26 April 2005 (03:00-03:00+1 LT) air mass around Japan (category 'D')

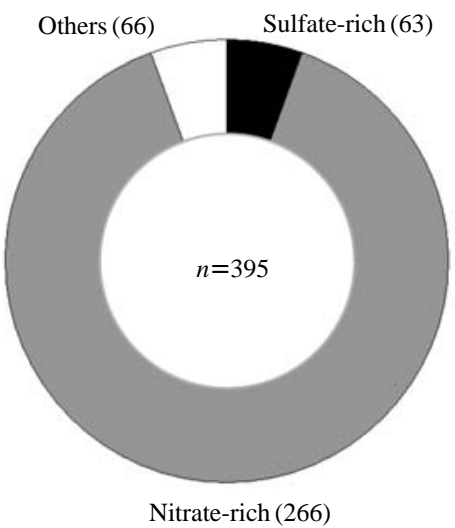

NOAA HYSPLIT MODEL

Backward trajectories ending at 12 UTC 26 Apr 05 FNL. Meteorological Data

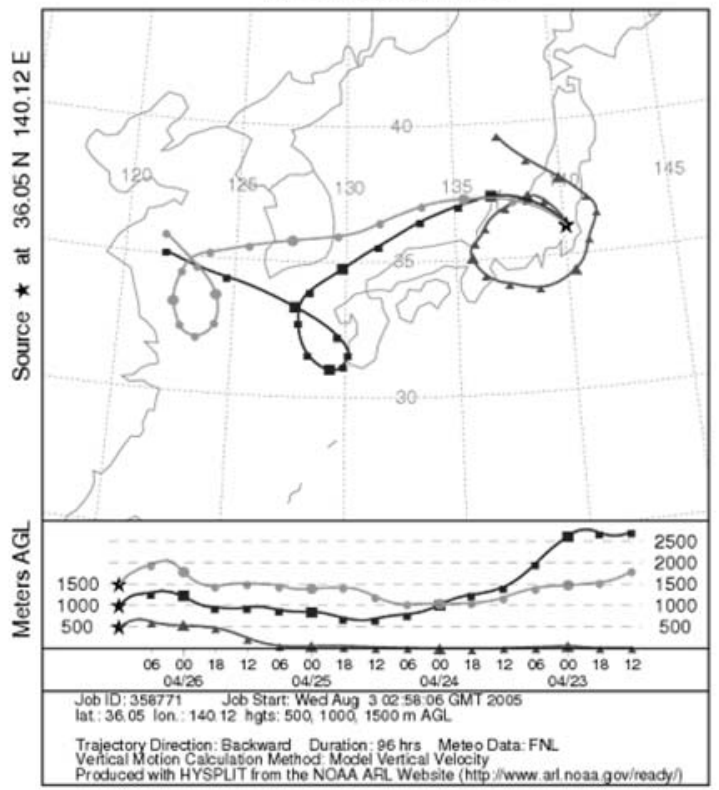

Fig. 4. (a) Air mass from the continent on 30 April 2005: fractions of prototypes and backward trajectory; (b) Regional air mass around Japan on 26 April 2005: fractions of prototypes and backward trajectory.

sulfate particles originating from the continent. The number of acquired mass spectra for sulfate-rich particles was 518 , which corresponded to $64 \%$ of the total 811 spectra observed during the period. Meanwhile, during the period when the air mass came from the Pacific Ocean (category ' $C$ ' in Fig. 2), and for regional air mass around Japan (category 'D'), the contribution of sulfate-rich particles was not significant. As 

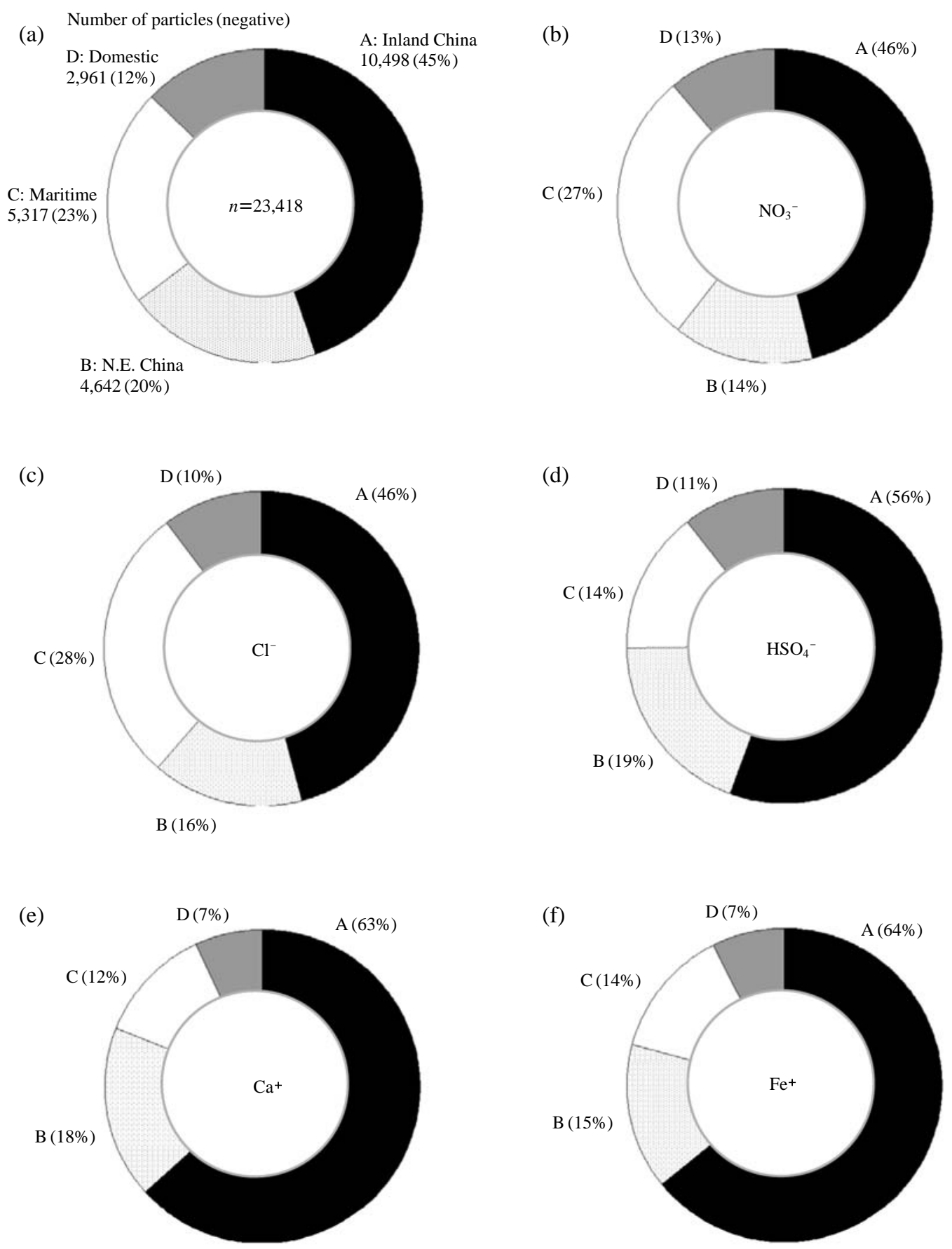

Fig. 5. Air mass dependence of (a) observed particle number during the negative ion detection, (b) the sum of intensities of observed $\mathrm{NO}_{3}{ }^{-}$ion $(m / z=62)$, (c) $\mathrm{Cl}^{-}$ion $(m / z=35)$, (d) $\mathrm{HSO}_{4}{ }^{-}$ion $(m / z=97)$, (e) $\mathrm{Ca}^{+}$ion $(m / z=40)$, and (f) $\mathrm{Fe}^{+}$ion $(m / z=56)$.

an example, the case on 26 April 2005 is shown in Fig. $4 \mathrm{~b}$. The trajectory analysis shows that the air mass traveled over the Japan Islands and that transport from the continent was insignificant during this period. The number of acquired mass spectra for sulfate-rich particles was 63 , which corresponded to $16 \%$ of the total
395 spectra observed during the period. Most of the particles were nitrate-rich $(67 \%)$, this implies that particles were influenced by the emission of $\mathrm{NO}_{\mathrm{x}}$ while the air mass passed over Japan. This result suggests that the air mass around Japan consisted of particles with significant nitrate and insignificant sulfate. 
It can be considered that such a 'background' air mass around Japan added to the air mass from the continent in the case of a dust event, and the mixed air was observed. As a result of the ART-2a analysis for the campaign in 2005 , it was suggested that sulfate originating from the continent was significant for particles observed in Japan, especially in the case of the dust event, as well as in the first campaign in 2004 (Matsumoto et al., 2006).

\section{2 Dependence of Chemical Components on the Meteorological Origin of Air Mass}

The ART-2a analysis is a powerful method to capture the trend of an enormous quantity of mass spectra preliminarily and automatically. However, the method is not effective to analyze the detailed compositions of individual particles. In this study, various compositions and their internally mixed states in individual particles were explored further with the peak intensities of mass spectra analyzed manually.

At first, data were sorted by air mass category and origins of the components were explored. Fig. 5 shows the air mass distribution of observed number of particles (negative ion mode) and accumulated peak intensities of selected species. Data from 06:00UT (15: 00LT (local time)) to 18:00UT (03:00LT+1, 03:00LT of the next day) were defined as 'pm' data and trajectories on 12:00UT were adopted. Fig. 5a indicates that the fraction of the air mass from inland China (category ' $A$ ' in Fig. 2) accounted for $45 \%$ of the observed number of particles. Such particles resulted from emission of mineral dust and sulfate on the continent and made the most significant fraction of particles detected in Japan in spring. As shown in Fig. 5b and 5c, some of the species (eg. $\left.\mathrm{NO}_{3}{ }^{-}, \mathrm{Cl}^{-}\right)$showed a distribution similar to the number of particles in Fig. 5a. Averaged intensities (i.e. division of accumulated intensities by the number of particles) of $\mathrm{NO}_{3}{ }^{-}$and $\mathrm{Cl}^{-}$ were not significantly different among the air mass origins. This result implies that nitrate and chloride were mixed with particles observed in Japan as back-ground components. Reasonably the sources of $\mathrm{NO}_{3}{ }^{-}$and $\mathrm{Cl}^{-}$ can be considered as anthropogenic emission and sea salt emission, respectively. The air mass category ' $\mathrm{A}$ ' gives a dominant contribution $(>50 \%)$ in the pie charts for $\mathrm{HSO}_{4}{ }^{-}, \mathrm{Ca}^{+}$and $\mathrm{Fe}^{+}$, while its contribution in those for $\mathrm{NO}_{3}{ }^{-}$and $\mathrm{Cl}^{-}$is relatively small $(<50 \%)$, as shown in Fig. 5. Anthropogenic emissions like coal combustion and mineral dust particles from inland China may be responsible for fractional enhancements in the category A for the $\mathrm{HSO}_{4}{ }^{-}$and $\mathrm{Ca} / \mathrm{Fe}$ distributions, respectively (eg. Streets et al., 2003; Akimoto and Narita, 1994).

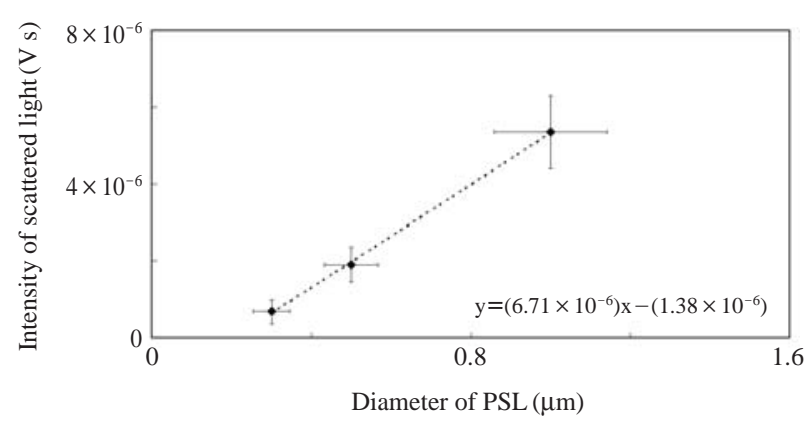

Fig. 6. Relationship between the diameter of polystyrene latex (PSL) particles and the scattered light intensity.

\section{3 Dependence of Chemical Components on the Physical Size of Particles}

To know the relationship between the scattered intensity of cw laser and the size of particles, standard PSL particles were introduced. During the observation, the relationship was acquired experimentally for $0.3-1.0$ $\mu \mathrm{m}$ particles as shown in Fig. 6 . Note that the diameter estimated by such scattered light intensity of one laser beam potentially has uncertainties due to differences of the position of particles in the laser beam, and scattering efficiencies among components (Lee et al., 2002). However, the diameter of each particle can be estimated from the light scattering method and it is possible to distinguish fine particles from coarse particles, at least. So we call the diameter from the scattered light an 'approximate diameter' to roughly acquire the information on the physical size of particle. It should be also noted that, in this study, to detect fine particles effectively, a frequency-doubled Nd:YAG laser (532 $\mathrm{nm}, 100 \mathrm{~mW}$ ) was applied as the detection laser. The aerodynamic lens was also modified, so that the instrument detected particles with their approximate particle size within $0.25-1.3 \mu \mathrm{m}$.

To explore the dependence of sulfate components on the physical size of the particles, the number distributions of sulfate-rich particles and sulfate-poor particles (including both nitrate-rich particles and others in Fig. 3) vs diameter were plotted in Fig. 7. Sulfate was more significant in fine particles for the submicron range. Note that this study focused on submicron particles while the previous study in Japan by Mori et al. (2003) reported coarse particles using a high volume sampler. Analysis of components by such a conventional sampling method is difficult for submicron particles due to the small quantities of components. It has been demonstrated that the single-particle TOFMS analyzer is capable of real-time determining the existence and the forms of components of individual submicron particles. 


\section{4 Correlations among Chemical Components}

In this section, internally mixed states are discussed by exploring correlations among chemical species in individual particles. To discuss the relationship among fractions of species in individual particles, correlations

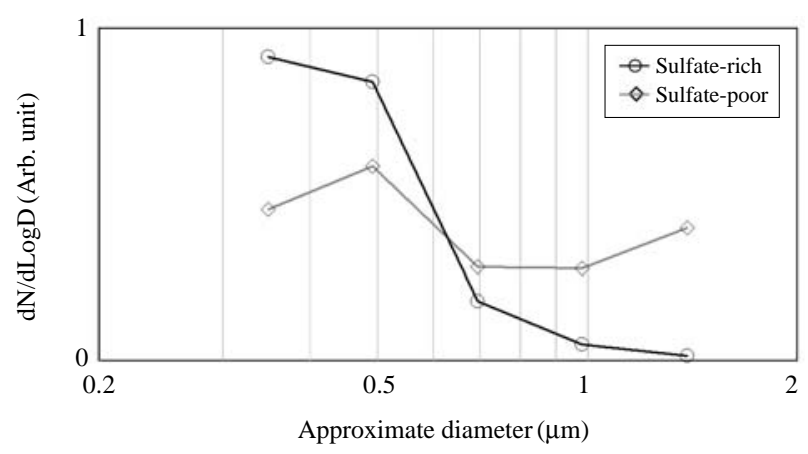

Fig. 7. Number distribution of sulfate-rich (circles) and other sulfate-poor (diamonds) particles as a function of approximate diameters.

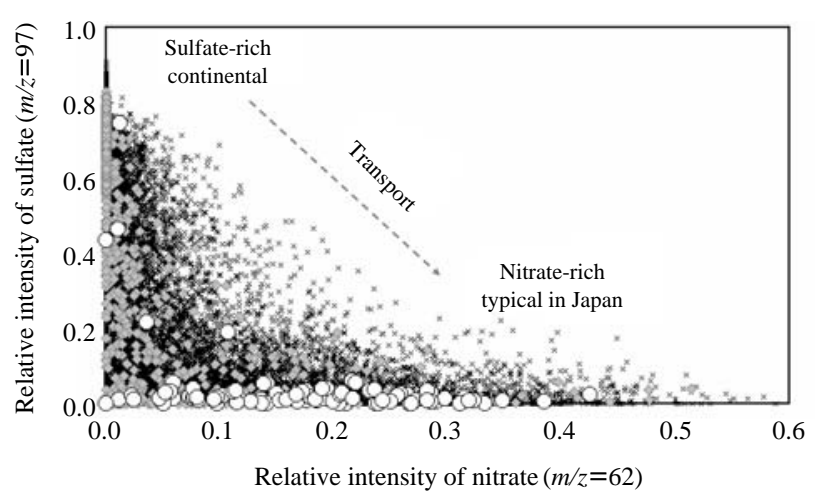

Fig. 8. Correlation between normalized intensities of sulfate $\left(\mathrm{HSO}_{4}{ }^{-}, m / z=97\right)$ and nitrate $\left(\mathrm{NO}_{3}{ }^{-}, m / z=62\right)$ during the whole period of observation: for the period of dust event on 30 April 2005 (gray diamonds) and of regional air mass on 26 April (open circles), small crosses represent other periods. among normalized peak intensities of two or three species are investigated. The normalized intensities were defined as

$$
I_{\mathrm{i}}^{\text {norm }}=I_{\mathrm{i}} / \sum I_{\mathrm{j}} \text {, }
$$

where $I$ is the peak intensity, $\mathrm{i}$ and $\mathrm{j}$ are mass numbers. For example, Fig. 8 is the correlation plot between normalized intensities of sulfate $\left(\mathrm{HSO}_{4}{ }^{-}\right)$and nitrate $\left(\mathrm{NO}_{3}{ }^{-}\right)$during the whole period of this observation. Individual points in the plot represent the internal mixing of sulfate and nitrate for the corresponding single particles. The origin point in Fig. 8 represents particles containing neither sulfate nor nitrate. Data points in Fig. 8 are classified into three categories as (1) dust event on 30 April 2005 (gray diamonds), (2) regional air around Japan on 26 April 2005 (open circles), and (3) others (small crosses). For the case of the dust event, both nitrate-rich and sulfate-rich particles were observed. For the case of regional air around Japan, nitrate-rich particles were dominant. Nitraterich particles during this period are considered as background particles in regional air. Sulfate-rich particles observed in Japan during the observation campaign had originated mainly from the continent, as shown in Fig. 5d. This result is consistent with our previous study (Matsumoto et al., 2006). The inverse correlation pattern between sulfate and nitrate could be due to their presence being dependent on different modes of transport.

The 'top-left-to-bottom-right' distribution of data points in Fig. 8 also represents the internal mixing of sulfate and nitrate during transport of the continental air mass to Japan. Individual points plotted in the 'topleft' region indicate the particles influenced by continental emission of sulfate while traveling to Japan. Such particles transported from the area 'A' and 'B' in Fig. 2 were mixed with nitrate before observation at Tsukuba. As the air mass traveled to Japan, the air including sulfate-rich particles was diluted by the 'background' air consisting of nitrate-rich particles. The content of nitrate increased toward the plot area

Table 1. Correlation coefficients between two chemical components for all observed data. Normalized intensities of ions are adopted. Values in parentheses are negative. The sign of the value represents the sign of the slope of the regression line.

\begin{tabular}{lcccccccc}
\hline \multirow{2}{*}{ Ions $(m / z)$} & \multicolumn{7}{c}{ Correlation coefficients $r$ with } \\
\cline { 2 - 8 } & $\mathrm{HSO}_{4}^{-}$ & $\mathrm{F}^{-}$ & $\mathrm{SiO}_{2}{ }^{-}$ & $\mathrm{SiO}_{3}^{-}$ & $\mathrm{NO}_{2}^{-}$ & $\mathrm{NO}_{3}^{-}$ & ${ }^{35} \mathrm{Cl}^{-}$ & ${ }^{37} \mathrm{Cl}^{-}$ \\
\hline $\mathrm{HSO}_{4}^{-}(97)$ & 1 & $\mathbf{0 . 9}$ & $(0.3)$ & $(0.1)$ & $(0.8)$ & $(0.6)$ & $(0.5)$ & $(0.4)$ \\
$\mathrm{F}^{-}(19)$ & & 1 & $(0.3)$ & $(0.1)$ & $(0.8)$ & $(0.7)$ & $(0.5)$ & $(0.4)$ \\
$\mathrm{SiO}_{2}^{-}(60)$ & & & 1 & $\mathbf{0 . 6}$ & 0.1 & 0.1 & 0.2 & 0.2 \\
$\mathrm{SiO}_{3}^{-}(76)$ & & & & 1 & 0.1 & 0.0 & 0.0 & 0.0 \\
$\mathrm{NO}_{2}^{-}(46)$ & & & & & 1 & $\mathbf{0 . 6}$ & 0.4 & 0.2 \\
$\mathrm{NO}_{3}^{-}(62)$ & & & & & & 0.4 & 0.1 \\
${ }^{35} \mathrm{Cl}^{-}(35)$ & & & & & & 1 & $\mathbf{0 . 9}$ \\
${ }^{37} \mathrm{Cl}^{-}(37)$ & & & & & & & & 1 \\
\hline
\end{tabular}


of the 'bottom right' region of Fig. 8. It should be noted that the data points approach the origin point when sulfate and/or nitrate are internally mixed with other components. Thus, such a correlation plot also indicates internally mixed states among sulfate, nitrate, and other components.

In the same way, internally mixed states can be explored by correlation analysis between arbitrary two components. This allows the sources, transport and chemical processes for a variety of components to be discussed. For representative combinations of negative ions, correlation coefficients during this observation are summarized in Table 1. Values in parentheses in Table 1 represent correlation coefficients for regression lines with a negative slope. For example, the correlation coefficient is +0.9 between ${ }^{35} \mathrm{Cl}^{-}(\mathrm{m} / z=35)$ and ${ }^{37} \mathrm{Cl}^{-}(\mathrm{m} / z=37)$. It is reasonable that a strong correlation was observed between these two ions, since sources, transport and chemical processes of both chloride isotopes are considered similar. Similarly, a positive correlation was observed for some combinations of similar sources, transport and chemical processes: $\mathrm{NO}_{2}{ }^{-}(m / z=46)$ and $\mathrm{NO}_{3}{ }^{-}(62)$ from nitrate; $\mathrm{SiO}_{2}{ }^{-}(\mathrm{m} / \mathrm{z}$ $=60)$ and $\mathrm{SiO}_{3}{ }^{-}$(76) from mineral dust. It is noteworthy that a strong positive correlation was observed between sulfate $\left(\mathrm{HSO}_{4}^{-}, 97\right)$ and fluoride $\left(\mathrm{F}^{-}, 19\right)$ ions. Detailed discussion on the observed features of fluoride ion containing particles is summarized in section 3.5.

Meanwhile, a negative correlation was observed for some cases as described above for sulfate and nitrate. Dissimilarities of sources, transport and chemical processes for the two components are suggested in such cases. In this study, sulfate and fluoride indicated negative correlations to most of the ions such as nitrate and sea salt $\left(\mathrm{Cl}^{-}\right)$. It is thought that sulfate and fluoride were dominated by emission and transport from the continent, and that different sources were significant for other components. As an example, a negative correlation between $\mathrm{HSO}_{4}{ }^{-}$and $\mathrm{NO}_{3}{ }^{-}$was observed as discussed in Fig. $8(r=-0.6)$.

To discuss internally mixed states of particles further, a ternary plot is useful (Sullivan et al., 2007a). As the first step of preparation of ternary plot, peak areas of three selected species for individual particles are normalized to make the sum of the three peaks unity. Then data for individual particles are plotted on the ternary map. A particle which mainly contains sulfate would appear close to the top vertex of the plot, primarily chloride at the left vertex, and primarily nitrate at the right vertex. Those points opposite the chloride vertex indicate internal mixture between sulfate and nitrate in individual particles. In this section, ternary plots of $\mathrm{HSO}_{4}{ }^{-}, \mathrm{NO}_{3}{ }^{-}$and $\mathrm{Cl}^{-}$are explored to investigate (a) Air mass from inland China (category 'A') 30 Apr. 2005, am. (03:00-15:00 LT)

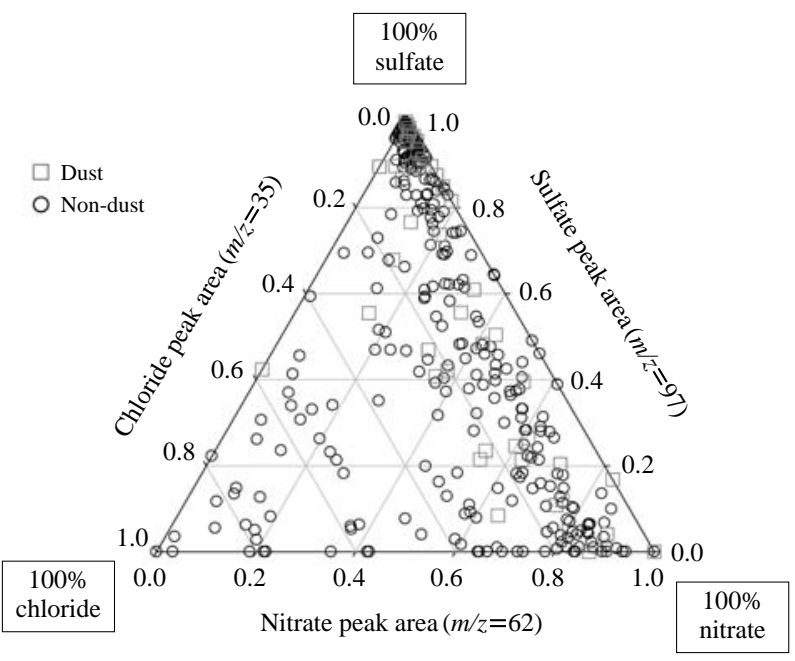

(b) Air mass around Japan (category 'D')

26 Apr. 2005, pm. (15:00-03:00+1 LT)

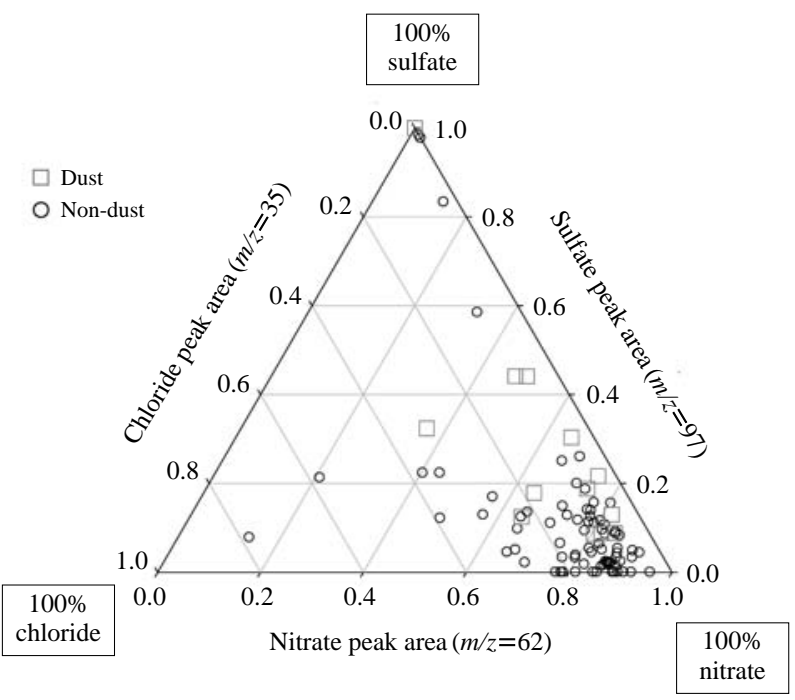

Fig. 9. Ternary plot among peak intensities of nitrate $\left(\mathrm{NO}_{3}{ }^{-}\right.$, $m / z=62)$, sulfate $\left(\mathrm{HSO}_{4}{ }^{-}, \mathrm{m} / z=97\right)$, and chloride $\left(\mathrm{Cl}^{-}, \mathrm{m} / z=\right.$ 35) where sulfate-rich particles appear at the top vertex, chloride-rich at the left vertex, and nitrate-rich at the right vertex: (a) continental air mass on 30 April 2005 (air mass category 'A'); (b) regional air mass around Japan on 26 April 2005 (air mass category ' $D$ '). Data points are categorized by the observed peak intensities of $\mathrm{SiO}_{2}^{-}(\mathrm{m} / \mathrm{z}=60)$ and indicated as follows: dust (open squares), and non-dust (open circles).

internally mixed states of continental sulfate, nitrate and sea salt. Data points are categorized by observed peak intensities of $\mathrm{SiO}_{2}^{-}(\mathrm{m} / \mathrm{z}=60)$ and indicated as follows: 'dust' (with significant $\mathrm{SiO}_{2}^{-}$signals), and 
'non-dust' (with no significant signal of $\mathrm{SiO}_{2}^{-}$).

The ternary plots of sulfate, nitrate and chloride are shown in Fig. 9a for the case of the dust event (on 30 April 2005, category 'A' in Fig. 2) and in Fig. 9b for the case of regional air mass (26 April 2005, category ' $D$ ' in Fig. 2). For the case of the dust event, dust particles from the continent consisted of highly abundant sulfate (open squares in Fig. 9a). Points around the nitrate vertex in Fig. $9 \mathrm{~b}$ were typical of background particles in Japan. Then points around the nitrate vertex in Fig. 9a were attributable to particles influenced by air over Japan. Points along the sulfate-nitrate axis represent individual particles that were transforming during transport from the continent to Japan, with nitrates gradually mixed with continental sulfate as the air mass traveled. On the 30 April 2005 (Fig. 9a) the dust particles are mainly along the sulfate-nitrate axis. This indicates that Asian mineral dust was important for transport of sulfate to Japan, and nitrate was internally mixed with the sulfate-rich particles as the air mass traveled over Japan.

From the ternary plots in Fig. 9, internal mixing among nitrate, chloride and sulfate can be explored further. Internal mixing of nitrate and chloride indicates chlorine loss process of sea salt particles owing to nitrate components as revealed in the ACE-Asia study (Sullivan et al., 2007a). Their observation was conducted onboard a ship in the marine boundary layer and so observed particles could be largely influenced by sea salt emitted just near the ship. During their observation, loss of fresh chlorine was captured in progress as the data points near the chlorine vertex in their ternary plot. Meanwhile, in this paper, many data points in the ternary plot were far from the chlorine vertex. In case of air mass from the continent (category A), some particles indicated significant $\mathrm{Cl}^{-}$ and chlorine loss in progress was captured, as shown in Fig. 9a. However, many particles were plotted on the line of ' $\mathrm{Cl}^{-} \sim 0.1$ ' where chloride was insignificant. In case of air mass around Japan (category D), chloride in particles was insignificant except for only a few particles. Such an insignificant chloride can result from (1) the distance from the fresh sea salt source, and (2) the $\mathrm{NO}_{\mathrm{x}}$ emission in Japan. It is reasonable that the chlorine loss already proceeded at the inland away from the coast (Pio and Lopes, 1998; Roth and Okada, 1998). Note that, as a source of chloride other than sea salt, the incineration of wastes can be considerable (Graedel and Keene, 1995). Moffet et al. (2008) recently reported the importance of internal mixing of chloride and metal components (eg. $\mathrm{Pb}, \mathrm{Zn}$ ) originating for the incineration in northern Mexico City. To discuss the contribution of chloride originating from sea salt, $\mathrm{Na}_{2} \mathrm{Cl}^{+}(m / z=81)$ and $\mathrm{NaCl}_{2}{ }^{-}(m / z=93)$ were useful as indexes of sea salt (Narukawa et al., 2007b; Arimoto et al., 2006). In this study, the correlation between $\mathrm{Cl}^{-}$and $\mathrm{NaCl}_{2}{ }^{-}$which could be simultaneously detected in the negative ion mode was explored. For all the particles observed in this study, the correlation was not clear $(r=+0.3)$. The anthropogenic emission of $\mathrm{Cl}^{-}$in Japan might be considerable. However, $\mathrm{Cl}^{-}$ was correlated with $\mathrm{NaCl}_{2}{ }^{-}$for the particles in which $\mathrm{NaCl}_{2}{ }^{-}$was detected significantly $(r=+0.8)$. It was suggested that $\mathrm{Cl}^{-}$originating from sea salt was also significantly captured. As a result of analysis of individual fine particles, it was implied that the chlorine loss in fine sea salt particles had already proceeded at Tsukuba, though the particles might be influenced by the anthropogenic sources of chlorine like the incineration. This is consistent with a previous study at Tsukuba, Japan (Roth and Okada, 1998). Meanwhile, for sulfate components, there is no clear correlation between sulfate and chloride. This suggests that oceanic source of sulfate was insignificant.

Internally mixed states of individual particles downstream of the outflow were characterized by some dominant factors: sulfate from the continent, nitrate attached later, chloride from sea salt, and mineral dust from the continent. Observation by the single-particle TOFMS analyzer clarified the characteristics of these particles in the downstream successfully.

\section{5 Fluoride}

It is remarkable that detected fluoride ion $\left(\mathrm{F}^{-}, m / z=\right.$ 19) were strongly correlated with sulfate $\left(\mathrm{HSO}_{4}{ }^{-}, \mathrm{m} / \mathrm{z}\right.$ $=97)$ as indicated in Table $1(r=+0.9)$. Such a strong correlation between sulfate and fluoride was observed also in the preliminary study in Japan (Matsumoto et al., 2006). Mori et al. (2003) reported detection of traces of fluoride in coarse Asian dust particles by filter sampling in Japan, though analysis of fluoride in fine particles was difficult owing to low amounts. In this study, data acquired by the single-particle TOFMS instrument was analyzed to investigate the existence of fluoride in individual submicron particles. Traces of fluoride ions were significantly detected owing to of the sensitivity of the TOFMS instrument, including the effect of the high electron affinity of the fluorine atom $(3.4 \mathrm{eV})$. To our knowledge, there have been few studies noting fluorine as a component of a single particle (eg. Beddows et al., 2004). Such a distinctive result on fluoride is explored further in this section.

The correlation between the ion signal intensities of fluoride and sulfate is shown in Fig. 10. A strong correlation was observed between fluoride and sulfate $\left(r^{2}\right.$ $=0.81$ ), indicating similarity of sources, transport and chemical processes of sulfate and fluoride. Especially, strong intensities of fluoride and sulfate ions were 


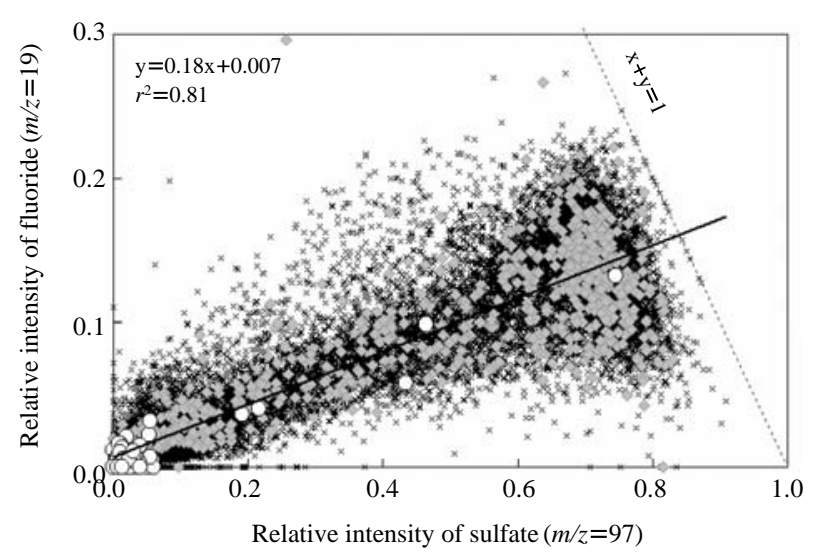

Fig. 10. Correlation between sulfate $\left(\mathrm{HSO}_{4}{ }^{-}, \mathrm{m} / z=97\right)$ and fluoride $\left(\mathrm{F}^{-}, m / z=19\right)$ : for the period of dust event on 30 April 2005 (gray diamonds) and of regional air mass on 26 April 2005 (open circles). The solid line is the regression line for all data points.

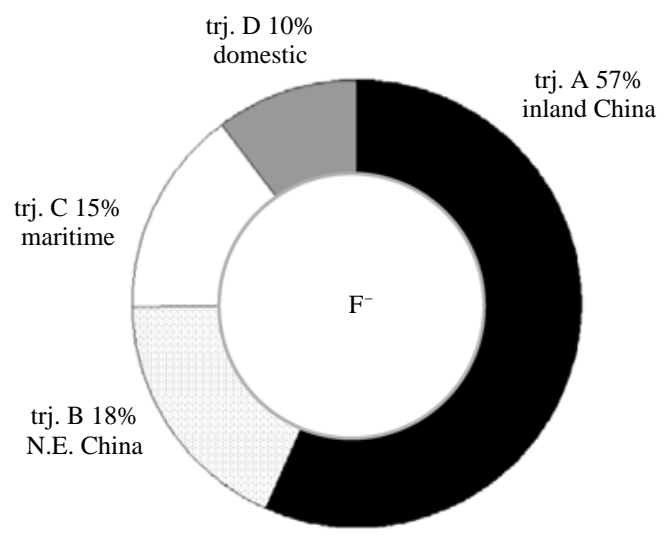

Fig. 11. Air mass dependence of the sum of observed intensities of $\mathrm{F}^{-}$ion $(m / z=19)$

observed in the case of the dust event (30 April 2005, gray diamonds in Fig. 10). The distribution of accumulated intensities of fluoride ion for 4 categories of air mass is shown in Fig. 11. Significantly strong signals of fluoride were detected in particles for the air mass from inland China (category ' $A$ ' in Fig. 2), similar to those of sulfate as shown in Fig. 5d. It was confirmed that fluoride was also concentrated in particles of the inland China air mass, therefore it is reasonable that the source of fluoride was similar to that of sulfate. Both sulfate and fluorine may be significantly emitted from coal combustion in China (Streets et al., 2003; Finkelman et al., 2002). Consequently, it was suggested that (1) fluorine compounds were emitted simultaneously with sulfur compounds by coal combustion in the continent, and (2) fluorine compounds were inter- (a) Air mass from inland China (category 'A') 30 Apr. 2005, am. (03:00-15:00 LT)

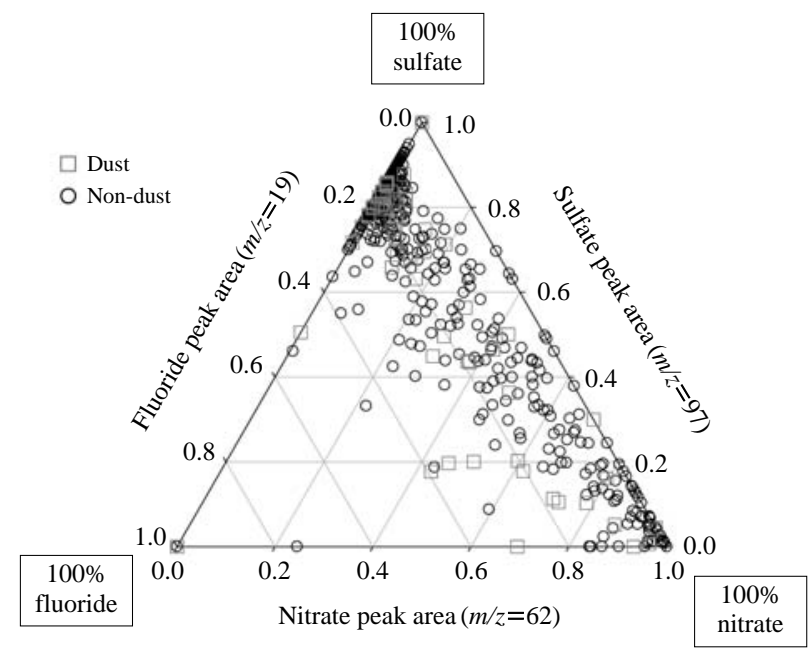

(b) Air mass around Japan (category 'D') 26 Apr. 2005, pm. (15:00-03:00+1 LT)

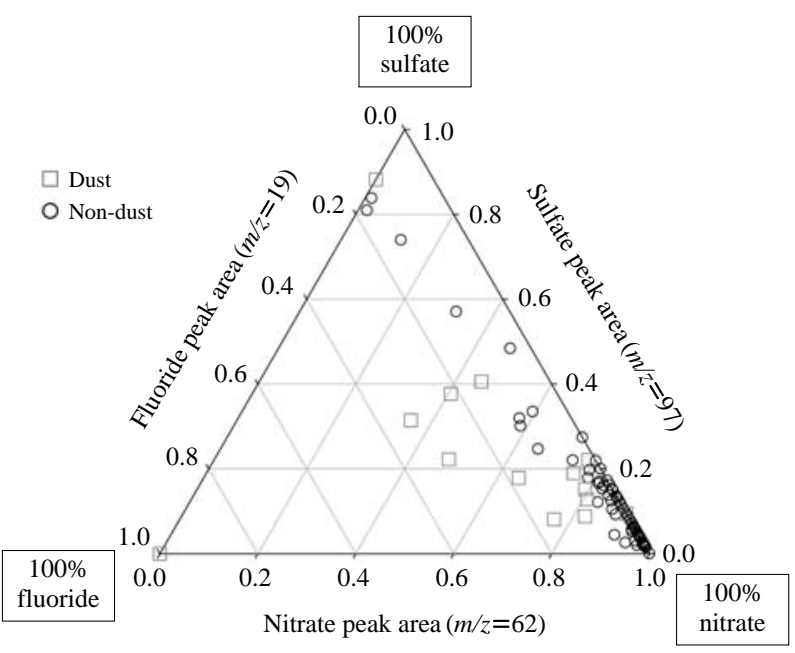

Fig. 12. Ternary plot of peak intensities of nitrate $\left(\mathrm{NO}_{3}{ }^{-}\right)$, sulfate $\left(\mathrm{HSO}_{4}{ }^{-}\right)$, and fluoride $\left(\mathrm{F}^{-}\right)$: (a) for the continental air mass on 30 April 2005 (air mass category 'A'); (b) regional air mass around Japan on 26 April 2005 (air mass category 'D'). Categories of data points are the same as Fig. 9.

nally mixed with particles as sulfate particles were growing and/or sulfate compounds were mixed with other particles during transport.

As one might guess from the high correlation between fluoride and sulfate, the size dependence of fluoride was similar to that of sulfate. The fraction of sulfate ion intensities was $66 \%$ for fine particles whose approximate diameters were less that $0.6 \mu \mathrm{m}$. For fluoride, the fraction was 59\%. It was found that fine 
particles were more effective than coarse particles for fluoride and sulfate to travel from the continent to Japan. The importance of fine particles for sulfate and fluoride transport was observationally clarified.

Finally, as shown in Fig. 12, ternary plots of the peak intensities of fluoride, nitrate and sulfate were investigated to demonstrate the internally mixed state for fluoride, (a) shows the results for particles in the dust event (category ' $A$ ') and (b) the results for particles in regional air mass around Japan (category ' $D$ ') were plotted independently. In the case of the dust event, the data points gathered around a straight line in the plot, when the air mass originated from the continent (categories 'A' and 'B'), as shown in Fig. 12a. Dust particles (open squares) were significant especially around the fluoride side. It was confirmed that Asian dust particles could be important as carriers of fluoride to Japan. Note that many of non-dust particles (open circles) were also observed around the fluoride side. This implies the importance of non-dust sulfate particles as carriers of fluoride. Meanwhile, Fig. 12b suggests that, in local air mass around Japan, both sulfate and fluoride were insignificant, while nitrate was dominant. The insignificance of sulfate in local air mass around Japan has been revealed in the ternary plot among chloride, nitrate and sulfate, as shown in Fig. $9 \mathrm{~b}$. This fact also supports the significance of continental source of sulfate and fluoride. Note that, it was shown that fluoride strongly correlated with sulfate but fluoride indicated weak inverse correlation with chloride (Table 1). Therefore it is implied that continental coal combustion was much more significant than oceanic source of fluoride observed in this study.

\section{CONCLUSIONS}

Chemical compositions of individual aerosols were observed during springtime in 2005 in a suburb of Tokyo in Japan utilizing a single-particle TOFMS instrument. Internally mixed states of submicron particles were focused on. Major conclusions are summarized as follows:

(1) As a result of ART-2a analysis, it was revealed that sulfate-rich particles originated from continental air mass as seen in the previous observation in 2004.

(2) From dependences of peak intensities on air mass origins, it was supported that sulfate originated from the continent. The sum of ion intensities of sulfate detected in particles originating from the continental air masses counted for $75 \%$ of that in all particles during the observation.

(3) Contents of nitrate did not depend on air mass origins, the nitrate components were observed inde- pendently of the air mass origin.

(4) The number distribution of sulfate-rich particles as a function of the particle diameters was investigated. Fine particles were dominantly sulfate-rich.

(5) Internally mixed states were investigated by analyzing correlations between chemical compounds. It was implied that the chlorine loss in fine sea salt particles had already proceeded at Tsukuba. It was noteworthy that fluoride ions were significantly detected, with fluoride correlated strongly to sulfate. It was indicated that sulfate and fluoride from the continent were significant especially for fine particles observed in Japan. To our knowledge, this is the first study to investigate fluorine components for individual submicron particles far downstream from the Asian continent.

In-situ, real-time, continuous observation using single-particle TOFMS is a promising method to discuss internally mixed states of particles by exploring chemical compositions, physical sizes, meteorological features of air mass origins, and the relationships among them.

\section{ACKNOWLEDGEMENTS}

The authors are grateful to Dr. T. Imamura (NIES) for supporting our experiments at the site. They also appreciate Prof. I. Uno (Kyushu University) for his support on CFORS. This work was supported by SENTAN, Japan Science and Technology Agency (JST).

\section{NOMENCLATURE AND SYMBOLS}

$I$ : Intensity of peak in mass spectrum. $\mathrm{m} / \mathrm{z}$ : Ion mass number divided by ion charge. $r$ : Correlation coefficient.

ACE-Asia : Aerosol Characterization Experiment in Asian Region.

ART-2a: Adaptive Resonance Theory 2A.

ATOFMS : Aerosol Time-Of-Flight Mass

Spectrometer.

CFORS : Chemical weather FORecast System.

LIDAR : LIght Detection And Ranging.

LT : Local time.

PSL : Polystyrene Latex.

TOFMS : Time-Of-Flight Mass Spectrometer.

UT: Universal time.

\section{REFERENCES}

Akimoto H. and H. Narita (1994) Distribution of $\mathrm{SO}_{2}$, 
$\mathrm{NO}_{\mathrm{x}}$, and $\mathrm{CO}_{2}$ emissions from fuel combustion and industrial activities in Asia with $1^{\circ} \times 1^{\circ}$ resolution. Atmospheric Environment, 28, 213-225.

Arimoto R., Y.J. Kim, Y.P. Kim, P.K. Quinn, T.S. Bates, T.L. Anderson, S. Gong, I. Uno, M. Chin, B.J. Huebert, A.D. Clarke, Y. Shinozuka, R.J. Weber, J.R. Anderson, S.A. Guazzotti, R.C. Sullivan, D.A. Sodeman, K.A. Prather, and I.N. Sokolik (2006) Characterization of Asian dust during ACE-Asia. Global and Planetary Change, 52, 23-56.

Bates T.S., P.K. Quinn, D.J. Coffman, D.S. Covert, T.L. Miller, J.E. Johnson, G.R. Carmichael, I. Uno, S.A. Guazzotti, D.A. Sodeman, K.A. Prather, M. Rivera, L.M. Russell, and J.T. Merrill (2004) Marine boundary layer dust and pollutant transport associated with the passage of a frontal system over eastern Asia. J. Geophys. Res., 109, D19S19, doi: 10.1029/2003JD004094.

Beddows D.C.S., R.J. Donovan, R.M. Harrison, M.R. Heal, R.P. Kinnersley, M.D. King, D.H. Nicholson, and K.C. Thompson (2004) Correlations in the chemical composition of rural background atmospheric aerosol in the UK determined in real time using time-of-flight mass spectrometry. J. Environ. Monit., 6, 124-133.

DeBell L.J., M. Vozzella, R.W. Talbot, and J.E. Dibb (2004) Asian dust storm events of spring 2001 and associated pollutants observed in New England by the Atmospheric Investigation, Regional Modeling. Analysis and Prediction (AIRMAP) monitoring network. J. Geophys. Res., 109, D01304, doi: 10.1029/2003JD003733.

Finkelman R.B., W. Orem, V. Castranova, C.A. Tatu, H.E. Belkin, B. Zheng, H.E. Lerch, S.V. Maharaj, and A.L. Bates (2002) Health impacts of coal and coal use: possible solutions. Int. J. Coal Geol., 50(1), 425-443.

Gard E., J.E. Mayer, B.D. Morrical, R. Dienes, D.P. Fergenson, and K.A. Prather (1997) Real-time analysis of individual atmospheric aerosol particles: Design and performance of a portable ATOFMS. Anal. Chem., 69(20), 4083-4091.

Graedel T.E. and W.C. Keene (1995) Tropospheric budget of reactive chlorine. Global Biogiochemical Cycles, 9(1), 47-77.

Huebert B., T. Bates, P. Russell, G. Shi, Y.J. Kim, K. Kawamura, G.R. Carmichael, and T. Nakajima (2003) An overview of ACE-Asia: Strategies for quantifying the relationships between Asian aerosols and their climatic impacts. J. Geophys. Res., 108, 8633, doi: 10. 1029/2003JD003550.

Jayne J.T., D.C. Leard, X.F. Zhang, P. Davidovits, K.A. Smith, C.E. Kolb, and D.R. Worsnop (2000) Development of an aerosol mass spectrometer for size and composition analysis of submicron particles. Aerosol Sci. Technol, 33, 49-70.

Lee S.H., D.M. Murphy, D.S. Thomson, and A.M. Middlebrook (2002) Chemical components of single particles measured with Particle Analysis by Laser Mass Spectrometry (PALMS) during the Atlanta SuperSite Project: Focus on organic/sulfate, lead, soot, and mineral particles. J. Geophys. Res., 107, 4003, doi:10.1029/ 2000JD000011.

Matsumoto J., K. Takahashi, Y. Matsumi, A. Yabushita, A. Shimizu, I. Matsui, and N. Sugimoto (2006) Scavenging of pollutant acid substances by Asian mineral dust particles. Geophys. Res. Lett., 33, L07816, doi: 10.1029/2006GL025782.

Middlebrook A.M., D.M. Murphy, S.-H. Lee, D.S. Thomson, K.A. Prather, R.J. Wenzel, D.-Y. Liu, D.J. Phares, K.P. Rhoads, A.S. Wexler, M.V. Johnston, J.L. Jimerez, J.T. Jayne, D.R. Worsnop, I. Yourshaw, J.H. Seinfeld, and R.C. Flagan (2003) A comparison of particle mass spectrometers during the 1999 Atlanta Supersite Project. J. Geophys. Res., 108, 8424, doi: 10.1029/ 2001JD000660.

Moffet R.C., B. de Foy, L.T. Molina, M.J. Molina, and K.A. Prather (2008) Measurement of ambient aerosols in northern Mexico City by single particle mass spectrometry. Atmos. Phys. Chem., 8(16), 4499-4516.

Mori I., M. Nishikawa, T. Tanimura, and H. Quan (2003) Change in size distribution and chemical composition of kosa (Asian dust) aerosol during long-range transport. Atmos. Environ., 37(30), 4253-4263.

Murphy D.M. and D.S. Thomson (1995) Thomson, Laser ionization mass spectroscopy of single aerosol particles. Aerosol Sci. Technol., 22, 237-249.

Murphy D.M., D.J. Cziczo, K.D. Froyd, P.K. Hudson, B.M. Matthew, A.M. Middlebrook, R.E. Peltier, A. Sullivan, D.S. Thomson, and R.J. Weber (2006) Singleparticle mass spectrometry of tropospheric aerosol particles. J. Geophys. Res., 111, D23S32, doi: 10.1029/ 2006JD007340.

Narukawa M., Y. Matsumi, J. Matsumoto, K. Takahashi, A. Yabushita, K. Sato, and T. Imamura (2007a) Realtime analysis of secondary organic aerosol particles formed from cyclohexene ozonolysis using a laserionization single-particle aerosol mass spectrometer. Analytical Sciences, 23(5), 507-512.

Narukawa M., Y. Matsumi, K. Takahashi, and A. Yabushita (2007b) Measurements of ammonium and sodium salt aerosol particles using a laser-ionization singleparticle aerosol mass spectrometer. Chemistry Letters, 36(7), 904-905.

Narukawa M., Y. Matsumi, J. Matsumoto, K. Takahashi, A. Yabushita, K. Sato, and T. Imamura (2008) Single particle analysis of secondary organic aerosols formed from 1,4-cyclohexadiene ozonolysis using a laser-ionization single-particle aerosol mass spectrometer. Bull. Chem. Soc. Jpn., 81(1), 120-126.

Nishikawa M., S. Kanamori, N. Kanamori, and T. Mizoguchi (1991) Kosa aerosols as eolian carrier of anthropogenic material. The Science of the Total Environment, 107, 13-27.

Phares D.J., K.P. Rhoads, A.S. Wexler, D.B. Kane, and M.V. Johnston (2001) Application of the ART-2a algorithm to laser ablation aerosol mass spectrometry of particle standards. Anal. Chem., 73(10), 2338-2344.

Pio C.A. and D.A. Lopes (1998) Chlorine loss from marine 
aerosol in a coastal atmosphere. J. Geophys. Res., 103, 25263-25272.

Roth B. and K. Okada (1998) On the modification of seasalt particles in the coastal atmosphere. Atmospheric Environment, 32(9), 1555-1569.

Shimizu A., N. Sugimoto, I. Matsui, K. Arao, I. Uno, T. Murayama, N. Kagawa, K. Aoki, A. Uchiyama, and A. Yamazaki (2004) Continuous observations of Asian dust and other aerosols by polarization lidars in China and Japan during ACE-Asia. J. Geophys. Res., 109, D19S17, doi: 10.1029/2002JD003253.

Streets D.G., T.C. Bond, G.R. Carmichael, S.D. Fernandes, Q. Fu, D. He, Z. Klimont, S.M. Nelson, N.Y. Tsai, M.Q. Wang, J.-H. Woo, and K.F. Yarber (2003) An inventory of gaseous and primary aerosol emissions in Asia in the year 2000. J. Geophys. Res., 108(D21), 8809, doi: 10.1029/2002JD003093.

Suess D.T. and K.A. Prather (1999) Mass spectrometry of aerosols. Chem. Rev., 99, 3007-3035.

Sullivan R.C., S.A. Guazzotti, D.A. Sodeman, and K.A. Prather (2007a) Direct observations of the atmospheric processing of Asian mineral dust. Atmos. Chem. Phys., 7, 1213-1236.

Sullivan R.C., S.A. Guazzotti, D.A. Sodeman, Y. Tang, G.R. Carmichael, and K.A. Prather (2007b) Mineral dust is a sink for chlorine in the marine boundary layer. Atmos. Environ., 41(34), 7166-7179.

Thomson D.S., M.E. Schein, and D.M. Murphy (2000) Particle analysis by laser mass spectrometry WB-57F instrument overview. Aerosol Sci. Technol., 33, 153169.

Uematsu M., R.A. Duce, J.M. Prospero, L. Chen, J.T. Merrill, and R.L. McDonald (1983) Transport of mineral aerosol from Asia over the North Pacific Ocean. J. Geophys. Res., 88, 5343-5352.

Uno I., G.R. Carmichael, D.G. Streets, Y. Tang, J.J. Yienger, S. Satake, Z. Wang, J.-H. Woo, S. Guttikunda, M. Uematsu, K. Matsumoto, H. Tanimoto, K. Yoshioka, and T. Iida (2003) Regional chemical weather forecasting system CFORS: Model descriptions and analysis of surface observations at Japanese island stations during the ACE-Asia experiment. J. Geophys. Res., 108, 8668.

Xiao H., G.R. Carmichael, J. Durchenwald, D. Thornton, and A. Bandy (1997) Long-range transport of $\mathrm{SO}_{\mathrm{x}}$ and dust in east Asia during the PEM B experiment. J. Geophys. Res., 102, 28589-28612.

Zhang D., Y. Iwasaka, G. Shi, J. Zand, M. Hu, and C. Li (2005) Separated status of the natural dust plume and polluted air masses in an Asian dust storm event at coastal areas of China. J. Geophys. Res., 110, D06302, doi: 10.1029/2004JD005305.

Zhao W., P.K. Hopke, X. Qin, and K.A. Prather(2005) Predicting bulk ambient compositions from ATOFMS data with ART-2a and multivariate analysis. Analytica Chimica Acta, 549, 179-187.

(Received 18 December 2008, accepted 7 June 2009) 